\title{
A six-year follow-up study of smoking habits and microvascular complications in young adults with type 1 diabetes
}

\author{
RN Sinha, AW Patrick, L Richardson, M Wallymahmed, IA MacFarlane
}

\begin{abstract}
Summary
One hundred insulin-dependent diabetic patients (age $<45$ years, 53 smokers) were followed for six years. The age, duration of diabetes and mean glycated haemoglobin levels, were comparable between the smokers and non-smokers. Microvascular complications (retinopathy and increased urine albumin excretion) were commoner and more severe in the smoking group at six years, particularly in heavy smokers. Of the $\mathbf{4 5}$ original smokers reviewed at six years, $12(27 \%)$ had stopped, six of whom had developed microvascular complications. Only two of the 'heavy' initial smokers, likely to be at most risk, had stopped smoking, and three original nonsmokers had started smoking.
\end{abstract}

Keywords: insulin-dependent diabetes, diabetic nephropathy, diabetic retinopathy, smoking, ischaemic heart disease

A diabetic patient who smokes has a 4-6 fold increased risk of developing ischaemic heart disease compared with a non-smoking, nondiabetic subject. ${ }^{1,2}$ Smoking may also promote the development and progression of diabetic microvascular disease, particularly diabetic nephropathy. ${ }^{1,3,4}$ Unfortunately, many young people with diabetes start smoking, ${ }^{5}$ and smoking prevalence amongst diabetic patients is similar to the non-diabetic population. ${ }^{6}$ Anti-smoking counselling has little initial impact on smoking habits, although long-term data is lacking. ${ }^{7,8}$

This study followed the smoking habits and the development of microvascular complications over six years in a cohort of young adult smokers with insulin-dependent diabetes mellitus (IDDM). The degree of nicotine dependence was measured by urine cotinine, a metabolite of nicotine.

\footnotetext{
Diabetes Centre, Walton Hospital, Liverpool L9 1AE, UK

RN Sinha

AW Patrick

L Richardson

M Wallymahmed

IA MacFarlane

Correspondence to Dr IA MacFarlane

Accepted 25 September 1996
}

\section{Patients and methods}

Fifty-three smokers with IDDM were recruited consecutively into a programme of anti-smoking counselling. ${ }^{7}$ None stopped smoking following this. During the same period, 47 patients who had never smoked were identified as a control group. At recruitment the two groups were comparable for age, duration of diabetes, and glycated haemoglobin (HbAl) concentration (table 1).

In all patients urine cotinine was measured
Table 1 Comparability of patient groups results are given as median (range) or mean (SD)

\begin{tabular}{lll}
\hline & $\begin{array}{l}\text { Smokers } \\
(n=53)\end{array}$ & $\begin{array}{l}\text { Non-smokers } \\
(n=47)\end{array}$ \\
\hline $\begin{array}{l}\text { Male/female } \\
\text { Age (years) }\end{array}$ & $\begin{array}{l}24 / 29 \\
30(18-43)\end{array}$ & $\begin{array}{l}30 / 17 \\
25(18-32)\end{array}$ \\
$\begin{array}{l}\text { Duration of diabetes } \\
\text { (years) }\end{array}$ & $8(1-23)$ & $6(1-21)$ \\
$\begin{array}{l}\text { HbA1 concentration } \\
(\%)^{\star}\end{array}$ & $10.3(1.9)$ & $9.9(2.4)$ \\
\hline
\end{tabular}

${ }^{\star}$ Non-diabetic range $5-8 \%$

as an objective assessment of the smoking load over the previous 24 hours. ${ }^{9}$ All non-smokers had a cotinine:creatine ratio (COT:CR) $<1.5$ $\mu \mathrm{g} / \mathrm{mg}$. The smoking group was subdivided into 29 'light' smokers (COT:CR $<7 \mu \mathrm{g} / \mathrm{mg}$ ) and 24 'heavy' smokers (COT:CR $>7 \mu \mathrm{g} / \mathrm{mg}$ ). Six years later, the two groups of patients were followed-up. Background retinopathy was defined as microaneurysms, haemorrhages or hard exudates in one or both eyes; proliferative retinopathy by the presence of soft exudates (cotton wool spots), active neovascularisation, or previous photocoagulation therapy. Nephropathy was identified by the measurement of urinary albumin excretion (Beckman rate nephelometric analyser) in at least two early morning urine specimens over a six-month period. A timed overnight urine sample confirmed the presence of microalbuminuria (urinary albumin excretion rate of 20$200 \mu \mathrm{g} / \mathrm{min}$ ). Macroproteinuria (albustix positive) was confirmed by a $24 \mathrm{~h}$ urinary protein excretion of $>500 \mathrm{mg}$.

Results are given as mean (SD) or median (range). Groups were compared using unpaired $t$-tests or chi-square tests as appropriate.

\section{Results}

After six years, 31 (58\%) smokers and 37 $(79 \%)$ non-smokers (chi-square $4.68 ; \mathrm{p}<0.05$ ) continued to attend the clinic. Eleven smokers and six non-smokers living locally, were traced and reviewed. Current smoking and retinopathy data were also obtained on three smokers who were attending clinics elsewhere, making a total of 45 smokers and 43 non-smokers with data available for analysis.

RETINOPATHY (TABLE 2)

Initially eight smokers and one non-smoker 
Table 2 Retinopathy status at entry to the study and after six years

\begin{tabular}{lllll}
\hline & $n$ & $\begin{array}{l}\text { Background } \\
\text { retinopathy }\end{array}$ & $\begin{array}{l}\text { Proliferative } \\
\text { retinopathy }\end{array}$ & Total \\
\hline $\begin{array}{l}\text { Initially } \\
\text { Smokers }\end{array}$ & 53 & 6 & 2 & $8(15 \%)$ \\
Non-smokers & 47 & 1 & 0 & $1(2 \%)$ \\
$\begin{array}{l}\text { After 6 years } \\
\text { Smokers }\end{array}$ & 45 & 8 & 4 & $12(27 \%)$ \\
Non-smokers & 43 & 5 & 0 & $5(12 \%)$ \\
\hline
\end{tabular}

Table 3 Nephropathy status at entry to the study and after six years

\begin{tabular}{lllll}
\hline & $n$ & $\begin{array}{l}\text { Micro- } \\
\text { albuminuria }\end{array}$ & $\begin{array}{l}\text { Macro- } \\
\text { proteinuria }\end{array}$ & Total \\
\hline $\begin{array}{l}\text { Initially } \\
\text { Smokers }\end{array}$ & 53 & 3 & 1 & $4(8 \%)$ \\
Non-smokers & 47 & 2 & 0 & $2(4 \%)$ \\
After 6 years & 40 & 9 & 2 & $11(28 \%)$ \\
Smokers & 39 & 6 & 0 & $6(15 \%)$ \\
Non-smokers & & & & \\
\hline
\end{tabular}

had retinopathy (chi-square 5.11, p<0.05). After six years, retinopathy was still more than twice as prevalent and more severe in the smoking group (chi-square $2.18, \mathrm{p}>0.05$ ).

\section{NEPHROPATHY (TABLE 3)}

Initially abnormal albumin excretion was rare. After six years, approximately twice as many smokers as non-smokers had evidence of nephropathy, although this difference was not significant (chi-square 2.63, $\mathrm{p}>0.05$ ).

\section{EFFECT OF SMOKING LOAD}

Eighteen (45\%) of the 40 smokers for whom complete data were available had either retinopathy or nephropathy at follow-up, compared with $10(26 \%)$ of the 39 non-smokers (chisquare 2.96: $p=N S$ ). Twenty-two of the 40 smokers were defined as 'heavy' smokers initially and $12(55 \%)$ of these had retinopathy and/or nephropathy after six years, compared with only six $(33 \%)$ of the 'light' smokers (chisquare $5.10 ; \mathrm{p}<0.05)$.

\section{SMOKING STATUS AT FOLLOW-UP}

Smoking data at follow-up were obtained from 45 of the original 53 smokers, $24(53 \%)$ of whom were 'heavy' and 21 (47\%) 'light' smokers initially. After six years, 12 (27\%) had stopped smoking, verified biochemically, most citing health concerns as the reason for stopping. Indeed half of those who had stopped had developed microvascular diabetic complications. However, only two (8\%) of the 'heavy'

1 Mulhauser I. Cigarette smoking and diabetes: an update Diabetic Med 1994; 11: 336-43.

2 Moy CS, LaPorte RE, Dorman JS, et al. Insulin dependent diabetes mortality: the risk of cigarette smoking. Circulation 1990; 82: $37-43$.

3 Sawicki PT, Didjurgett U, Mulhauser I, Bender $R$ 3 Sawicki PT, Didjurgett U, Mulhauser I, Bender $R$ progression of diabetic nephropathy. Diabetes Care 1994; 17: $126-7$

4 Chaturvedi N, Stephenson JM, Fuller JH. The relationship between smoking and microvascular complications in the EURODIAB IDDM Complications Study. Diabetes Care 1995; 18: 785-92.

5 Masson EA, MacFarlane IA, Priestley CJ, Wallymahmed M, Flavell H. Failure to prevent or reduce nicotine addiction in young people with diabetes. Arch Dis Child 1992; 67: 100-2.

Learning/summary points
- smokers with diabetes have a $4-6$ fold
increased risk of developing ischaemic heart
disease compared with non-smoking, non-
diabetics
- smoking is associated with diabetic micro-
vascular complications (nephropathy,
retinopathy); this may be a stimulus to stop
smoking
- anti-smoking counselling has little effect
initially on young diabetic smokers

smokers had stopped smoking compared with $10(48 \%)$ of the 'light' smokers (chi-square $8.84, \mathrm{p}<0.01)$. One of the 'heavy' smokers who stopped had received retinal photocoagulation and a renal transplant. Unfortunately three $(7 \%)$ of the original non-smokers had started smoking and two of these had developed background retinopathy.

\section{Discussion}

Patients with diabetes may give false smoking histories, ${ }^{8}$ therefore, studies of smoking and diabetic complications which have not used objective markers, may not be valid. In this study, we verified and quantified smoking and when the smokers and non-smokers were compared after six years, retinopathy and nephropathy were more prevalent in the smokers, particularly in the 'heavy' smoking group. These findings support the hypothesis that smoking is associated with the development of microvascular complications although a causal relationship has not been proven. Possibly, smoking reflects particular lifestyle patterns which increase the risk of developing complications. For example, smokers were more likely to default from clinic.

The psychosocial problems of diabetes and the burden of diabetes management add to the difficult task of smoking cessation. Most diabetic smokers are aware of the health hazards and wish to stop $^{6}$ but have great difficulty in so doing. ${ }^{5,7,8}$ We found that $27 \%$ of the original smokers assessed after six years had stopped, which is encouraging. However, most of these had been 'light' smokers originally. The development of microvascular complications may be the main stimulus to stopping in many patients. There are huge benefits in not smoking for diabetic patients ${ }^{10}$ and more effective strategies are clearly needed.

6 Horsley JR, Barrett JA, MacFarlane IA. Diabetic patients: smoking habits and beliefs. Health Trends 1987; 19: 13-5. 7 Ardron M, MacFarlane IA, Robinson C, Van Heyninghen C, Calverley PMA. Anti-smoking advice for young diabetic smokers: is it a waste of breath? Diabetic Med 1988; 5: 66770 .

8 Bodmer CW, MacFarlane IA, Flavell H, Wallymahmed M, Calverley PMA. How accurate is the smoking history in newly diagnosed diabetic patients? Diabetes Res Clin Pract 1990; 10: 215-20.

9 Peach B, Ellard GA, Jenner PJ, Morris RW. A simple inexpensive test of cigarette smoking. Thorax 1985; 40: $351-7$.

10 Yudkin JS. How can we best prolong life? Benefits of coronary risk factor reduction in non-diabetic and diabetic subjects. BMF 1993; 306: 1313-8. 